\title{
ROOTING OF QUBAHAN SCHOOL AN ANALYTICAL STUDY TO ARCHITECTURAL ITEMS (SPATIAL CONFIGURATION AND FORMALITY ELEMENT OF INTERIOR FACADES OF QUBAHAN SCHOOL)
}

\author{
RAEEd S. AhMed Al-Numman \\ Dept. of Architecture, University of Mosul-Iraq
}

\begin{abstract}
In recent years, trends have emerged focusing on exploration the architectural identity through the study of the domestic architecture properties, as a result appeared a large number of architectural studies that have targeted the crystallize the privacy of every society. The most striking feature in the Kurdistan architecture are the buildings that express cultural identity of the Kurdish community, also they are basis upon which the architectural identity, which represented the cultural identity to the Kurdish community, in various fields (social, cultural, political, historical, humanitarian, immigration and defensive tactics and Immunization). All of these elements and others represented the cultural identity of the Kurdish society and reflected directly on the architectural identity of the community, the pattern of local architecture in Kurdistan region is real reflection of the nature of the society. Culture and level of economic and social status, therefore architecture formed an original part of the cultural identity as a responsive basic need of society and the nature of the living conditions. The lack of attention to local architectural character of the mountains regions, led to the appear buildings do not belong to the identity of the local architecture, and due to the lack of research for local architecture Characteristics, it will study the architectural style (the principles form of traditional face) in ancient amadiyah city buildings, and the design characteristics of its buildings, so that architects benefit from it in modern buildings design.
\end{abstract}

KEYWORD: architectural identity, spatial configuration, principles form, local architecture, Qubahan School.

\section{INTRODUCTION}

The city has Features different from of other city by its urban formed, fabric, spatial configure and architecture beside its culture, arts, traditions and cultures. all these constitute its identity, The determination of the formation properties in architectural and urban design of the old areas is aimed at highlighting the features those characteristics and linked to their community values, which is a catalyst for development processes that take place for those areas, that any process aimed at urban improvement that adopt Maintenance Building architecturally and structurally only and provision of facilities and services that you need, without regard for the inherent design values them will lead to the loss of their content, and puts it in the near future, the area does not have any ingredients stimulate the maintenance and re-developed, especially if they have deteriorated again after development.

\section{QUBAHAN SCHOOL (QUBAHAN MADRASAT)}

\subsection{Introduction}

Qubahan Kurdish ancient school, next to the Imam Youssef Mosque, in the valley of Hqlvat, or Alrobar, or Alsolaf, down the mountain, which stabilizes above town (Amadiyah). Built it Sultan (Hussain Crown) (1534-1570), and name Qubahan: Maybe we infer from Vibrio on pollinator letter, the weighting label following the example like of (Quba Mosque) the first mosque in Islam. (Carl Novjak, p.p245-250 2011).

\subsection{School history}

The school build has been associated with alzankiyeen in the second century AD, as well as with a very late period of the Emir Badinan Prince Hussein) 1480 - 1534 (, Sultan Hussein al-Wali 1524-1573 (or qabad from 1573 to 1584 but other sources linking the beginning of the school with Imam Muhammad Baqir ibn Yusuf who lived in the tenth century AD, while the Sultan Hussein alBadi was a reconstruction of the school. (To Tonna,p213,1990) In the end of the sixteenth 
century (description Amadiyah school) Iamedi (as the most important regional center for religious studies), but without naming Qbhan. The extraordinary attention from Sultan Hussein for the school through expansion of the school and increase the donation) Waqf that appears by seal found in several books, which remained in the big school Library. (To Tonna,p233,1990)

\section{2 description of the site}

The remains of the school building, known locally as Qubqhan school are located extra muros , ,920 m NW from today's eastern town entrance ,situated on the terrasse edge below the steep SE slop of the valley stretching between the hill of
Bses $(1920 \mathrm{~m})$ and the rocky plateau on which the town is laid . the wide green valley surrounds the town plateau on the north and the west sides with river Ribari as it's the axis Fig(1), Sonderdruck aus Zeitschritft, p179, 2011.The school was accessible from the mousl gate (western gate ) traversing the difference in elevation of about $200 \mathrm{~m}$. Isolated ruins and traces of masonry dispersed in watered gardens, orchards and surrounding of the building, indicate that the Qubahan School might have been a part of a wider, now disappeared settlement area (Carl Novjak, p.p245-250 2011).

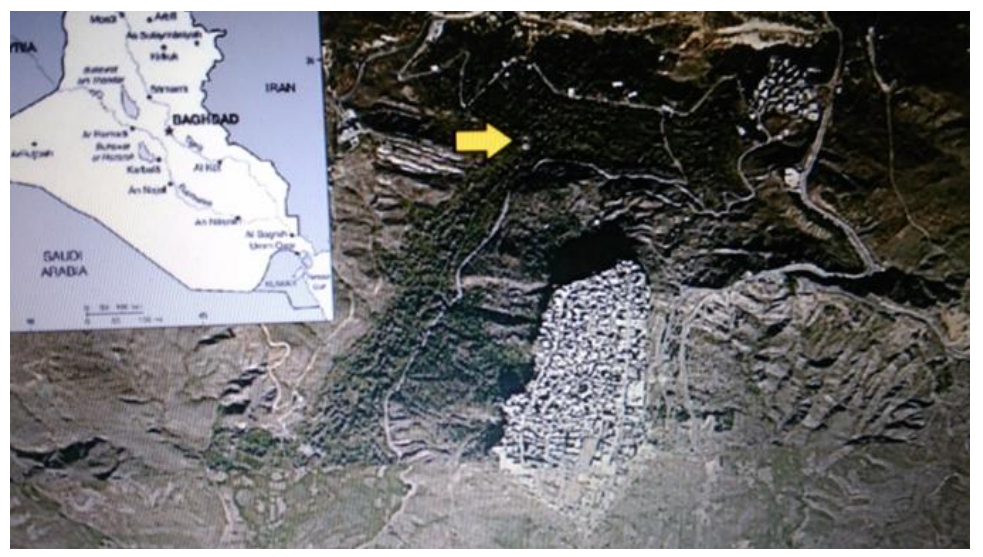

Fig. (1): location of amidi and qubahan school http:// Iraq map .org google earth 2010

Reference: Sonderdruck aus Zeitschritft, p178, 2011.

The site, once the most prominent center of literary culture in the region, is paradoxically not at all reflected in the available historical sources the first laconic note about the already ruined school occurred in the travelogue of mark Sykes (Carl Novjak, p.p245-250, 2011). the origin of the building is only included in several contradictory oral the zangide $12^{\text {th }}$ century $\mathrm{AD}$ as well as much later with Bahdenan Amir Hassan (1480-1534) .sultan Husain wali (1534-1573) or Qubad (15731584) anther tradition linked the beginning of school with Imam Mohamed Baqer bin Youssef living repute

\section{THE ARCHITECTURAL CONFIGURATION ITEMS}

Qubahan School is a rectangular shape building has length of 75 meters and width 30 meters. With courtyard in the center surrounded by suites and rooms, on two floors. The second floor was dedicated to the management, two rooms for teachers, and a special pavilion for the kitchen and bathroom, additional to the library wing. The ground floor has five halls, each hall has domed. (David Chalabi, p.153, 1927)

\subsection{Entrance school}

The only entrance to the school is located in the West End, as a prominent mass

from the line facade of about 1.5 meters and extends the entrance a block of about 3.5 meters, in same level of the ground floor, up from the surrounding spaces a little bit so it is accessed simple ramp and the entrance mass containing the stairs to access the first floor of the building. Fig (2)

\section{2 ground floor}

The Qubahan complex school is composed of cluster of spaces, the nuclease of which, without line plan and dimension of $(38 \mathrm{~m} * 23 \mathrm{~m})$ consists of two main parts 
The first one south building with central domed hall $(8.2 \mathrm{~m} * 8.4 \mathrm{~m})$, smaller cupolaerd room adjacent on the east and west sides (originally two, only one partly preserved) and with a portico in the front of the north entrance .according to an undated historic sketch of the school horizontal plans, we are able to determine the purpose of this part at least in the last phase of its existence the central hall was used as teaching hall, the lateral rooms served as library and room for teaching(Carl Novjak, p.p245-250 2011).

The second: three winged building with great Iwan, situated axially on the opposite side of the domed hall, and 8-10 rooms for students and teachers on the left and right sides. this part centered around the stone -paved courtyard and was connected to the portico by solution room in the east wing and connecting part in the west wing where the only entrance into the complex and stairs to the first floor are located .( Carl Novjak, , p.p245-250, 2011)

\subsection{First floor}

The first -floor superstructure composite two rooms above the Iwan and the left part of the north wing. The building has no apparent remain of a minaret. This nucleus is extended in the southwest by three parts, the mausoleum, the court, and the mosque. (Carl Novjak, p.p245-250 2011).
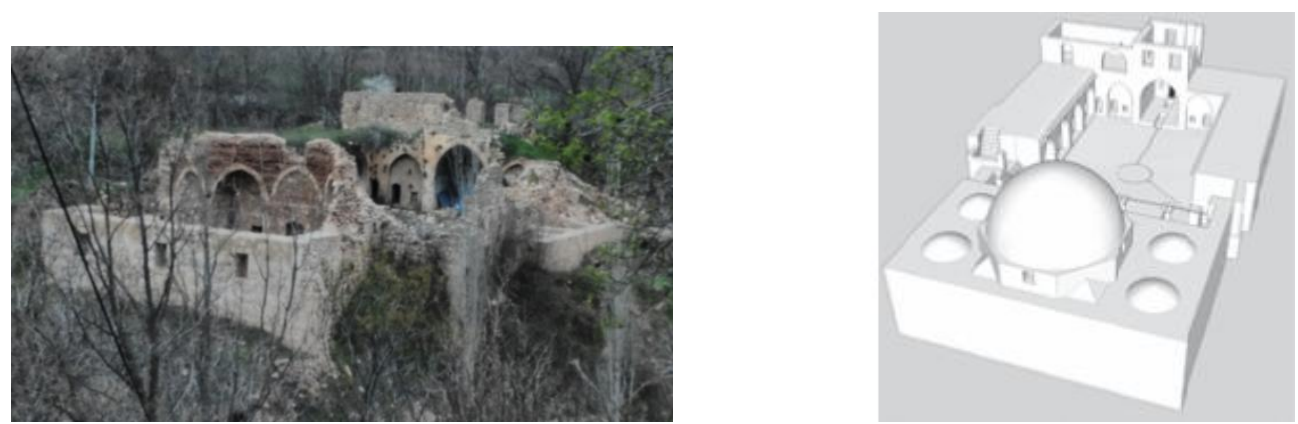

Fig. (2): Qubahan School Reference: researcher Reference: Carl Novjak, and Nermin Ali, 2011

\section{PREVIOUS STUDIES}

Architectural heritage represents the crossing symbol for the nation's identity in thought and culture, as it is a reflection of social, political, economic and religious life of the people, was the buildings are a reflection of the nature of the entire life of the population, both through regular homes, schools, mosques, baths or palaces. this legacy integrated textile does not It must be preserved Bstyallosail using either practical ways like "restoration" or to carry out the process of documentation of those buildings. Most studies on Qubahan School were limited to documentary and archaeological aspects of the structural elements, and its construction and historic case. Like. Carl Novjakand Nirmin Mohamed 2011, "the study of archaeological school Qubahan" which is focused to the building elements and its components and descriptive, analysis of these components. Other studies have focused on archaeological discoveries in and around the site. But some of these studies have focused on decoration, which began its stones eroded some of the details because of the demolition, and these studies documenting these subjects and analyzed.

\section{RESEARCH ISSUE}

This study is one of very few studies which have investigated of the architectural analytical study of the School Qubahan both on the horizontal plan level and at the level of architectural elevation details.

\section{THE RESEARCH AIM}

The main research aim is to identify the identity of Kurd architecture through rooting one of the most important historical buildings in the Kurdistan region (Qubahan School). Also the research is contributes the first logical and architectural analysis, detect and identify spatial configuration and guideline of the principles, properties depend on the formation of the internal elevations through the application and analysis of these properties on one of the most important architectural and historical significant value (Qubahan School). The search will be a first stage 

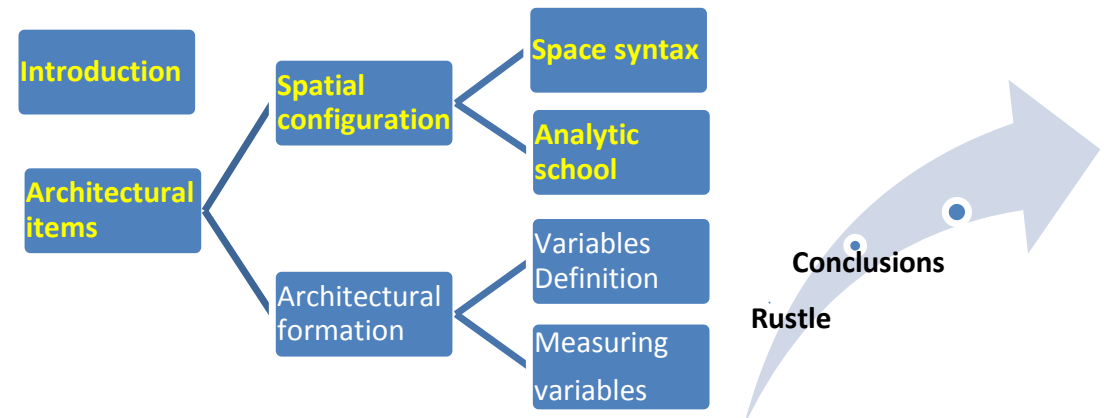

Fig. (3): Research structure Reference: researcher

\section{MEASUREMENT TOOLS}

\section{1 space syntax}

Theoretically, space syntax is rooted in a problem that seems a first sight to forbid a structure-function theory for either buildings or cities. the ideas about the relationship between society and the space organization was the basis that depend on the space syntax studies. The space has social component element and the community has a spatial element. The rules of the installation space is a set of technologies used to represent the measurement and interpretation of space systems for urban settlements and individual buildings.

\subsubsection{Spatial measurements}

Structural properties of spaces characterized by two types of space systems characteristics that can be measured after the establishment of the alignment scheme (Justified graph) for such systems, namely.

\subsubsection{Space depth}

As refers (Monteiro), the depth refers to the number of (optical - dynamic) steps that separates the two spaces on the main space (Amorim and Luiz, 1997, p.2), To find out the depth of the space by rules Space Syntax . Represent the system by Justified graph, then numbered the spaces from basically space, all spaces have same depth if it in the same level. The depth determines from (0) in basically space, and spaces are numbered continue over the basically space.

\subsubsection{Measuring integration spaces Real Relative Asymmetry (RRA)}

This feature is linked to the index (symmetry - asymmetry) which refers to the relative depth of the space or shallow relative to the rest of the spaces of the building (a measure of a totalitarian) in calculating as following:
First, the rate of depth space calculation according to the following steps

Create alignment scheme

Calculate the depth of each space in the scheme for the main space. The depth of each space is equal to the number of spaces that must pass through them to move from that space to the main space.

Extraction rate of space depth mediated by the following equation :

$\mathbf{M D}=\sum \mathbf{D} / \mathbf{K}-\mathbf{1}$.

As the MD: space depth rate

D: amounts of total depth for all spaces System

$\mathrm{K}$ : number of spaces in system

Second: calculate space integration, the value of (Real Relative Asymmetry

The value of the relative integration (R.A) of space for all the other spaces in the system account mediated by the following equation (Hillier, Hanson 1984, p. 108:(

R.A = 2 (MD -1) / K - 2

As that:.

R.A: Relative Asymmetry

MD: Space depth rate

$\mathrm{K}$ : Number of spaces in the system

\subsubsection{Calculate the values of average relative asymmetry (RRA)}

It is adjusted resulting from the previous equation. where is adjusted R.A for each space in the system with the value of depth scheme fundamentally shape (Diamond Shaped) where the depth of the form core represents an intermediate state between the maximum rate of the depth of the space when it is organized spaces in a linear sequence relative to the main space and the lowest 
rate when all spaces are directly linked with the main space.

The value of the average relative asymmetry, which represent the final value of the index of the degree of integration spaces of the following equation account.

$$
\text { RAA = R.A / DK }
$$

While

RAA: Real Relative Asymmetry (degree of integration(

R.A: Relative Asymmetry

$\mathrm{D} . \mathrm{K}=$ relative asymmetry of a diamond or pyramid shape pattern of $\mathrm{k}$ spaces, the D.-value..

The values of space integration ranging between $(0-1)$ as a space at the high of the integration when the value of space integration is equal to $(0)$ when the values of the space integration of space equal to (1) the space will be at the high of isolation.

(Hillier, Hanson, 1984, p. 113).

\subsubsection{The characteristics of the system as a whole.}

Include the intersection of nuclei.

It includes the intersection nucleus integration or isolation with nucleus strong or weak control respectively.

\subsubsection{The strong nucleus of Comprehensiveness control}

It represents match the nucleus of a strong control, which represents $25 \%$ of the spaces of the system that holds the highest degree of communication with the nucleus of integration, which represents $25 \%$ of the spaces of the system that carry a higher degree of integration and reflect the core of the spaces with the highest degree of careerism as a point of orientation for the movement of all spaces other system. (Hillier and Hanson, 1984: p. 144).

\subsubsection{The weak nucleus of Comprehensiveness control}

Represent Match nucleus weak control, which represents $25 \%$ of the spaces of the system that carries the least degree of communication with the nucleus of the insulation, which represents $25 \%$ of the spaces of the system that carries the least degree of integration and reflect this kernel for more spaces unarmed and least extreme careerism as a point of orientation for the movement of all the spaces of the system other. (Hillier and Hanson, 1984: p. 165)

\subsection{The measurements of architectural formation}

The similar composition principles in architecture and the arts morphological there is a close link between the concept of modulation and architecture Valcecchel lieutenant Architecture Valamarh used artistic composition same principles, and can be expressed in these principles, it is the process of organizing the plastic components in the form of images and fun and where the items are collected under a certain order to reach a result, the work of a coherent serve the purpose of the expressions given any sense (Abdul Razzaq,p.76, 2008) the processes of composition and configuration in fact, starting from the first moments that prescribed architectural the design Valamarh consists of formations composed in space and used shape and texture and material, light and color as parts included in the regulation, the advantage of being a cohesive unit is disjointed uniform, consistent and coherent and Alczykl is the name given to the sum of the parts and their relationships with each other and between them and the spaces inside or around it, and that determines the whole a distinctive character for that one thing or the body (Ching, F. D.K, p.112,1997). Valcecchel architect representing the external sensory body of material consisting of a system of properties of the elements Alcklaah relations sensory them both in the horizontal plane or in the formation volumetric or vacuum, Valcecchel architectural prescribed by the designer using visual vocabulary Fine essential elements and guideline principles and foundations of design to turn it into blocks and spaces of a given system (Samir, p.67, 2005). Yebda architectural design knowledge of the sensory characteristics of the various forms of regular ones, and then concludes some fine values those relations between the blocks and blanks architectural control. As can be free from these values then in the experience of dealing with irregular shapes, to bring it into a regular configurations, by three-dimensional modeling in which the senses of vision and touch play a role in the construction of architectural thought. The most important architectural composition Principles findings from previous studies can be defiant, to:

An asymmetrical architectural composition may be particularly successful applying the principle of „bar centricity” or „gravimetry” , according to which the composition of volumes and of architectural details should be made such that the mass balance is ensured, so the masses have the same ,weight" in relation with the axes, even if the volumes are contrasting (e.g. - an assembly consisting of several bodies - primary 
volumes, each having its own axe of symmetry, the assembly being asymmetrical because the variation of the distances of these axes from the principle axis, but getting balanced through the masses of the component bodies composition. (Tzonis, p.126, 1984). The axes of composition are defined in the work as imaginary lines of reference, ordering lines of the disposal in plan, sections facades around them and in their sense it develops the compositional series of volumes, architectural surfaces and elements which compose the building.

\subsubsection{Symmetry}

Symmetry was derived from the word symmetry of the Greek symmetria and that means we can recognize the symmetry when observe and compare the Butterfly "wings the same procedure." That mean the wing on the right or left side of the butterfly almost perfectly matches with the other wing. As a term in architecture the symmetry, it is a method of classification of building elements on the basis of their physical properties. As it described the left and right images replica of the butterfly's wings by a number of conditions, including the line, or mirror symmetry. In architecture, there are many different types of symmetry. Such as plane symmetry, rotational points, rotational symmetry, etc.

\section{Line, mirror (reflect) symmetry}

Two halves of the whole are each other's mirror images. If it applies to exactly the same or centered, equidistant from the sides or ends of a larger object or structure. When Passing in the middle the object as a line called the Line or Mirror Symmetry, refers to the placement of an object so that a structure demonstrates a symmetric appearance. It involves the aesthetics of symmetry and perhaps.
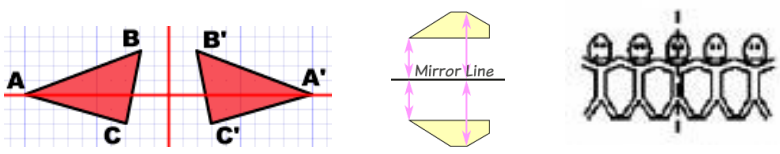

Reference: (http://www.nsta.org/publications/story.asppx?id=53719)

Mirror symmetry

2 .Point symmetry: A symmetry point there is a one (fixed) point in a design that is differs from the others. Or symmetry point is when the shape draws on a single point and this point will not change, whatever the type of symmetrical, (as a rotation). This point represents the center of the object or the symmetry center.
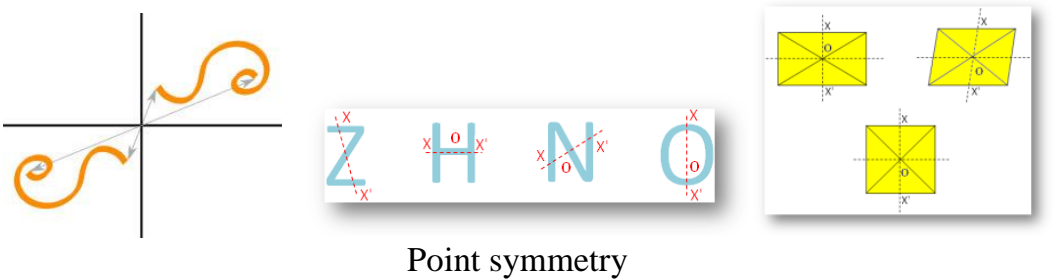

1978). The figure below represent plane symmetry

3. Plane symmetry a pattern is a planar image that is invariant under two linearly independent and isometric translations in the plane. Furthermore, in both directions there is a translation of minimal length preserving the pattern. (Doris Schattschneider, p.p445-450, includes structures in three dimensions, whereby the one side of the structure is a mirror image of the other. The plane symmetry is often referred to three dimensions symmetry, if we want comparison with line symmetry

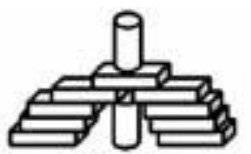

Plane symmetry 
Reference: (http://www.nsta.org/publications/story.asppx?id=53719).

\section{Rotational symmetry;}

if the figure is turned about a fixed point; it is called rotation. This rotation can be: clockwise or anticlockwise .cylindrical; spiral , helical and ,rotational symmetry creates when an object, element or the structure appears as if it can be rotated around its axis, and it creates in the same position at least two or more times. Foe examples the angle of rotation angle is the angle of turning during rotation. A quarter turn represent a rotation of $90^{\circ}$. While a half turns represent a rotation of $180^{\circ}$.when a rotation of $360^{\circ}$ means a full turn. The shapes below have rotational symmetry if it put more than once during a complete rotation.
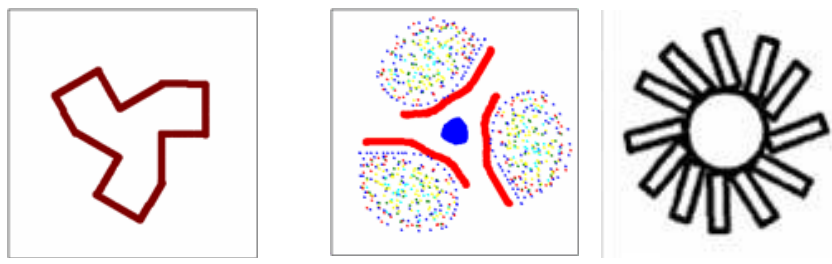

Rotational symmetry

Reference: (http://www.nsta.org/publications/story.asppx?id=53719).

\subsubsection{Rhythm}

\subsubsection{Rhythm}

The rhythm defined as the meaning of a patterned of repetition, repetition, or movement in actions or buildings In design, rhythm is the regular, harmonious recurrence of a specific element, often a single specific entity coming from the elements of line, shape, form, color, light, shadow, and sound. . (Salingaros, p.7, 2000).

\subsubsection{Factors create rhythm}

Rhythm, as defined, is cause by repetition. Repetition is a method of processing information. In language arts, repetition is a persuasive strategy used to affect or coordinate trends, especially when the use of the terms repeatedly with different form (Boisvert, p145, 2011), applying different ways of repetition, different results of emotional inspiration are created, which shown that language is an instrument or tool for serving certain purposes ( Boisvert, p155,2011) .

\subsubsection{Rules causing rhythm in design.}

Rules create rhythm can be described as a set of operating procedures applied to create forms. In any design, there are many functional design issues that must be considered and rhythm can or cannot be one of them. Yet, regardless of whether rhythm has been considered as a design issue or not, as long as a rhythm appeared in a building's design, its phenomena demonstrate the effort of thinking about specific arrangements. The items below the examples explaining the rules applied for creation, which are categorized by the nature of repetition (Tzonis, p.132, 1984)

1. Regular rhythm is repetition in shapes a regular rhythm is created by repeating an element through regular repetition and the repeated elements are same in length, or size. In draft design, it could be a form that re-occurs by some in certain types or intervals to constitute a design. (Graves, p.178, 1951).

2. Structure rhythm is repetition in structure a structure rhythm is created by combining arches or girders and to form repetitive structural spans, and these structural elements are similar in dimensions or size to maintain the structural properties of balance. (Boisvert, p189, 2011)

3. Spatial rhythm is repetition in functions of spaces recur to repetitive functional requirements in buildings program or similar accommodate, for example, standardized units of guest rooms in hotel, classrooms in school, or patient rooms in hospital used in diffrent buildings typologies. 


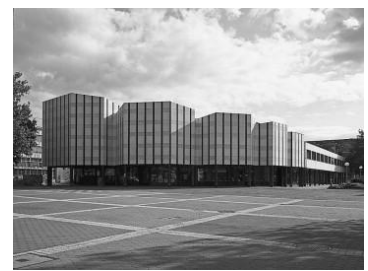

(Spatial rhythm)

Reference: (http://dx .doi.org/10.1016/j.foar.2012.02.003)

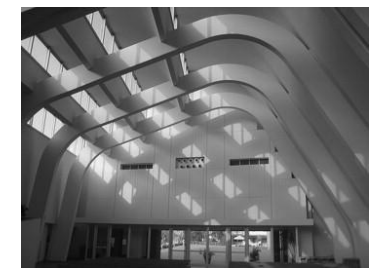

(Structure rhythm):

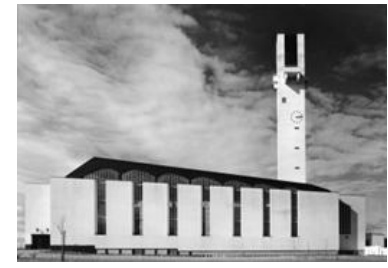

(regular rhythm)

\subsection{Proportionality}

According Roman architect Vitruvius there are "three conditions of a good building to be commodity (Beneficial), firmness (the strength) and delight (aesthetic).

The proportion plays an important role in all previous conditions, it also provides guidelines for the development Beneficial in the blanks, to design structural systems, and to create an aesthetically object. Proportions of the space can various dramatically in how observer feeling toward, the design rise can affect whether the building seems to welcome, or impressive.

Proportion technically denotes a ratio; there are two kinds of proportion. Form Perrault notes, the first one is difficult to perceive, describes the magnitudes that the various parts of a building have in relation to each other or to the whole. while the second, which is called summitry that consists of the relationship of all the parts together, according to this notes, the first kind of proportion consists of a series of quantitative relationships that are difficult to see with the unaided eye and presumably can only be revealed by measuring instruments, while the second is a relationship among the parts of a whole that is universally distinguishable by all human beings as either aesthetically correct or defective. Properties of a small part, is also the measure of the segment $\mathrm{XZ}=\mathrm{x}$ if $\mathrm{ZY}=\mathrm{y}$ is taken as unit of length. (Rubensten, p. 67, 1969) according that we can classify proportion as:

\section{Geometrical Proportionality}

"Proportion is the equality of two ratios." If we have create two ratios $\mathrm{X} / \mathrm{Y}, \mathrm{Z} / \mathrm{M}$, between the two "Quantities " [Similar objects or quantities] X and $\mathrm{Y}$ on one side, and the two quantities $\mathrm{Z}$ and $\mathrm{M}$ on the other, the equality $\mathrm{X} / \mathrm{Y}=\mathrm{Z} / \mathrm{M}$ ( $\mathrm{X}$ is to $\mathrm{Y}$ as $\mathrm{Z}$ is to $\mathrm{M}$ ) means that the four magnitudes $\mathrm{X}, \mathrm{Y}, \mathrm{Z}$, $\mathrm{M}$ are connected by a proportion. (Rubensten , $\mathrm{p}$. 68, 1969) If $X, Y, Z, M$ are parts of straight lines measured by the lengths $\mathrm{X}, \mathrm{Y}, \mathrm{Z}, \mathrm{M}$ we have between these measurements, these numbers, the equality $\mathrm{x} / \mathrm{y}=\mathrm{z} / \mathrm{m}$; this is the geometrical proportion, called intermittent, generally case when $\mathrm{X}, \mathrm{Y}, \mathrm{Z}, \mathrm{M}$, are different, and continuous geometric proportion if two of these numbers are identical. The typical continuous proportion is therefore $\mathrm{x} / \mathrm{y}=\mathrm{z} / \mathrm{m}$, is called the proportional or geometrical mean between $\mathrm{x}$ and $\mathrm{z}$. It is the geometrical proportion, discontinuous or continuous, which is generally used or referred to in aesthetics, especially in architecture (Rubensten , p. 70, 1969)

\section{The Golden ratio.}

The Greeks noticed that three sides at least are necessary to express a proportion; such the case of continuous proportion $\mathrm{x} / \mathrm{y}=\mathrm{z} / \mathrm{m}$. But we can try to create a greater simplification by reducing to two the number of the terms, and making $\mathrm{z}=\mathrm{x}+\mathrm{y}$. So that (if for example and $b$ are the two segments of a straight line of length c) the continuous proportion becomes: $\mathrm{x} / \mathrm{y}=\mathrm{y} / \mathrm{x}+\mathrm{y}$ or $(\mathrm{y} / \mathrm{x})=(\mathrm{y} / \mathrm{x})$ +1 . (Rubensten , p. 77, 1969) If one makes $y / x=$ $\mathrm{x}$, one sees that $\mathrm{x}$, positive root of the equation $\mathrm{x} 2$ $=\mathrm{x}+1$, is equal to $1=\mathrm{I} 5 /$. This is the ratio known as "Golden ratio"; when it exists between the two parts of a whole (here the segments $x$ and $y$, the sum of which equals the segment $z$ ) it defines between the whole and its two parts a proportion such that "the ratio between the greater and the smaller part is equal to the ratio between the whole and the greater part.

\section{PRACTICAL STUDY}

From ground floor of the qubahan school that explain in fig (4) we developed the convex map and justified graph of qubahan school Fig (5) and Fig (6), considering the exterior spaces as a basis space. It emerged following characteristics, as shown in Tables No. (1, 2). 


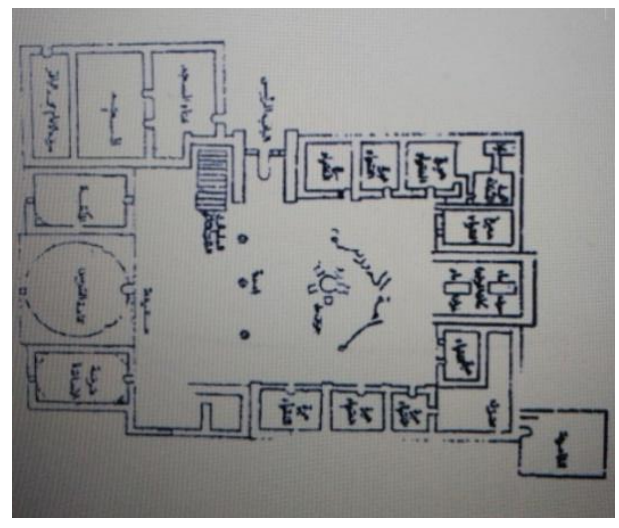

Fig. (4): ground floor of Qubahan School Reference: Sonderdruck aus Zeitschritft, p181, 2011.

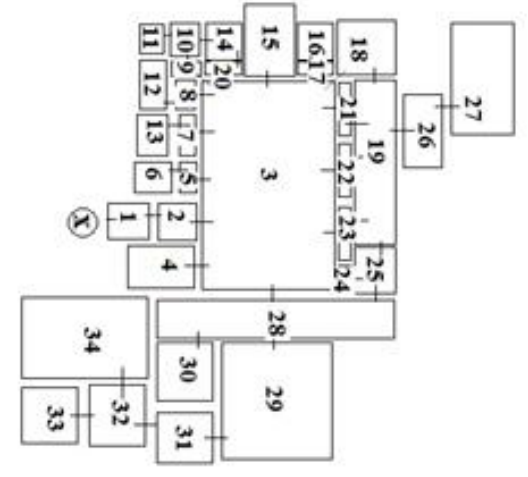

Fig. (5): convex map of qubahan school

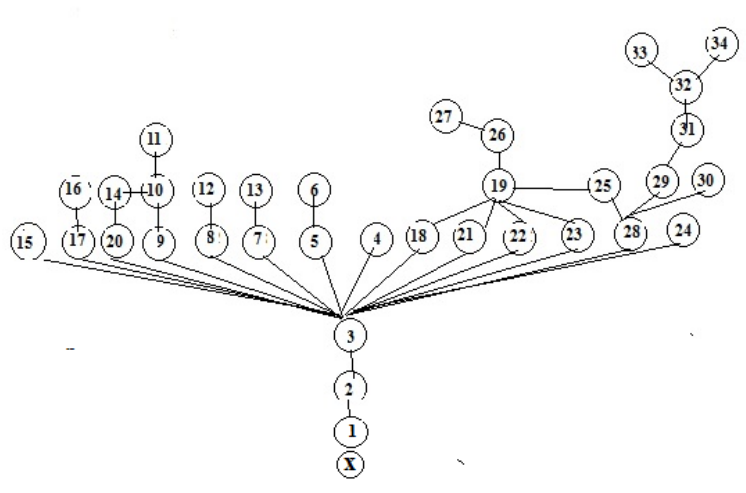

Fig. (6): justified graph of qubahan school

Reference: researcher

Table (1): result of depth spaces level and Nucleus intersected

\begin{tabular}{ccccc}
\hline Case study & No. of spaces & Depth level & Depth / no. of spaces & control \\
\hline Qubahan school & $\mathbf{3 5}$ & $\mathbf{8}$ & $\mathbf{2 3 \%}$ & $\mathbf{\square}$ \\
\hline
\end{tabular}

Table (2): result of integration spaces

\begin{tabular}{|c|c|c|c|c|c|c|}
\hline Mosque & Corridor & courtyard & classroom & office & entrance & Space function \\
\hline$\bullet$ & $\bullet$ & $\bullet$ & & & & Qubahan school \\
\hline
\end{tabular}




\section{1 results depth level spaces}

After setting convex map and justified graph of Qubahan school, considering the exterior spaces as a basis space.as in figure $(5,6)$ emerged the following characteristics, as shown in Table (1).(

8.1.1 Results associated with the characteristics of the structure of the system as a whole the intersection of nucleus.

The school Characterized by medium nucleus of Comprehensiveness control.

8.1.2 Results associated with the feature of symmetry - asymmetry (Integration spaces)

By using space syntax program, were calculated the degree of integration of all the spaces of the school, and the results were as in Table (2)(

The results showed a clear divergence in the integration of some of the main spaces of the school values while spaces achieved (courtyard, the corridors and classrooms) closely in the integration and insulation values, since it occurred within the nucleus of integration for (courtyard, corridors and Mosque) and the nucleus of insulation for classrooms these values varied space for the main entrance and administrative section. It was the entrance space values (.588) while those values for the average courtyard equal $(0.41)$, while the classrooms achieved values equal (0.834), and the integration values of administrative spaces equal (0.934).

9.2 The analytic results of the principles of architectural composition.

Flowing, the elevation of interior space of courtyard of Qubahan School Fig (7) that used as sample of study. Thus adoption of the style of the Formalist analysis to the elements of the internal interfaces of the school that have been documented by the researcher, through the theoretical framework form, as follows.

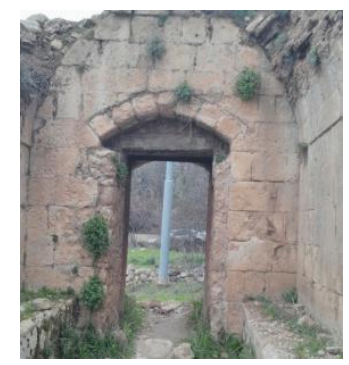

Entrance elevation

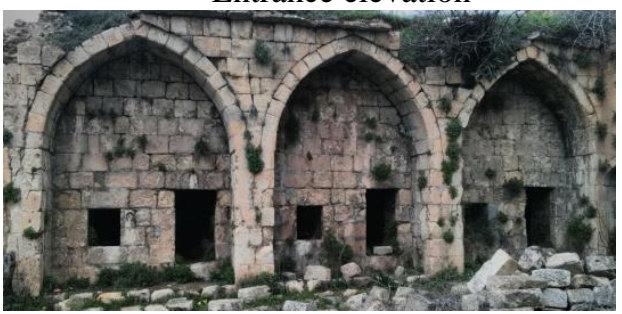

(Courtyard) south elevation

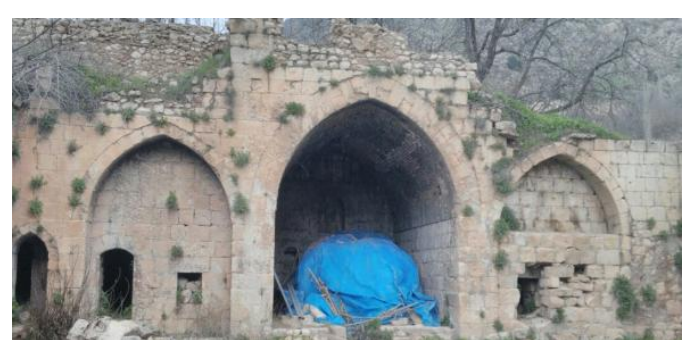

North part elevation (great Iwan)

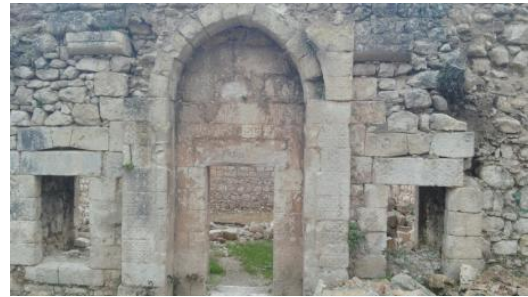

(courtyard) West elevation

Reference: researcher

Fig. (7): different elevation of interior space of courtyard of Qubahan School 


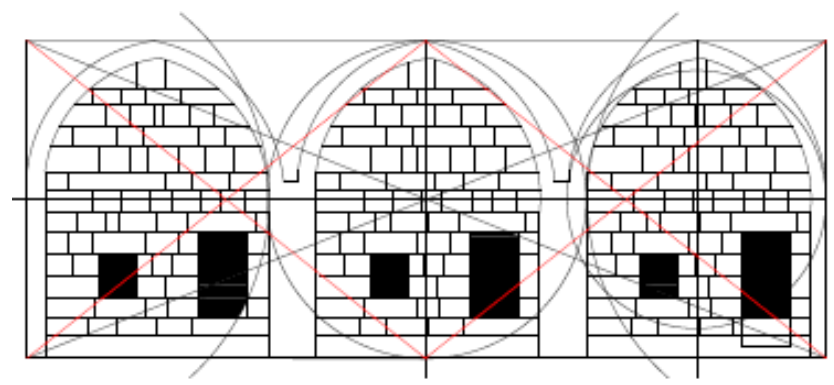

(Courtyard) west elevation

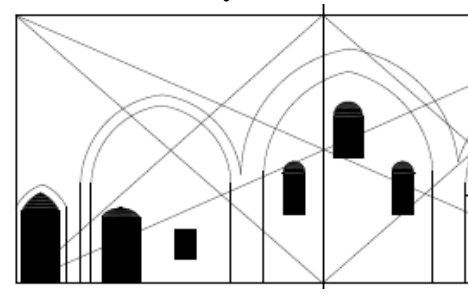

North part elevation Great Iwam Reference: researcher

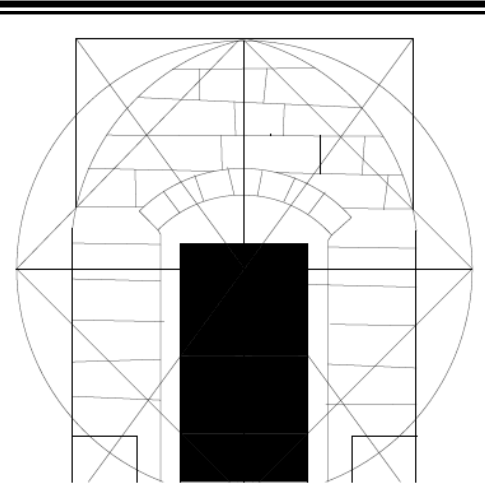

entrance elevation

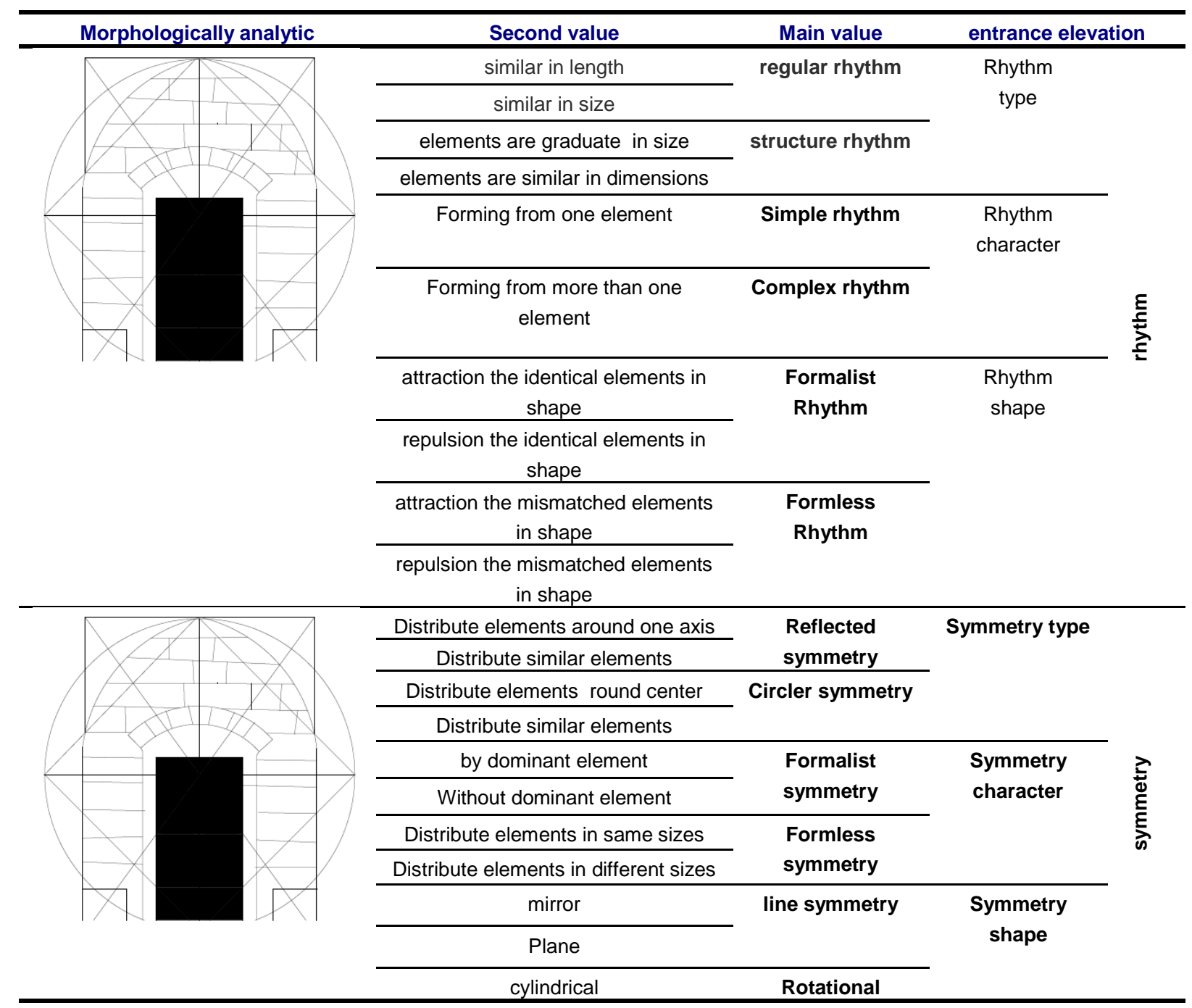


Journal of University of Duhok, Vol. 20,No.1 (Pure and Eng. Sciences), Pp 26-41, 2017

eISSN: 2521-4861 \& pISSN: 1812-7568

https://doi.org/10.26682/sjuod.2017.20.1.4

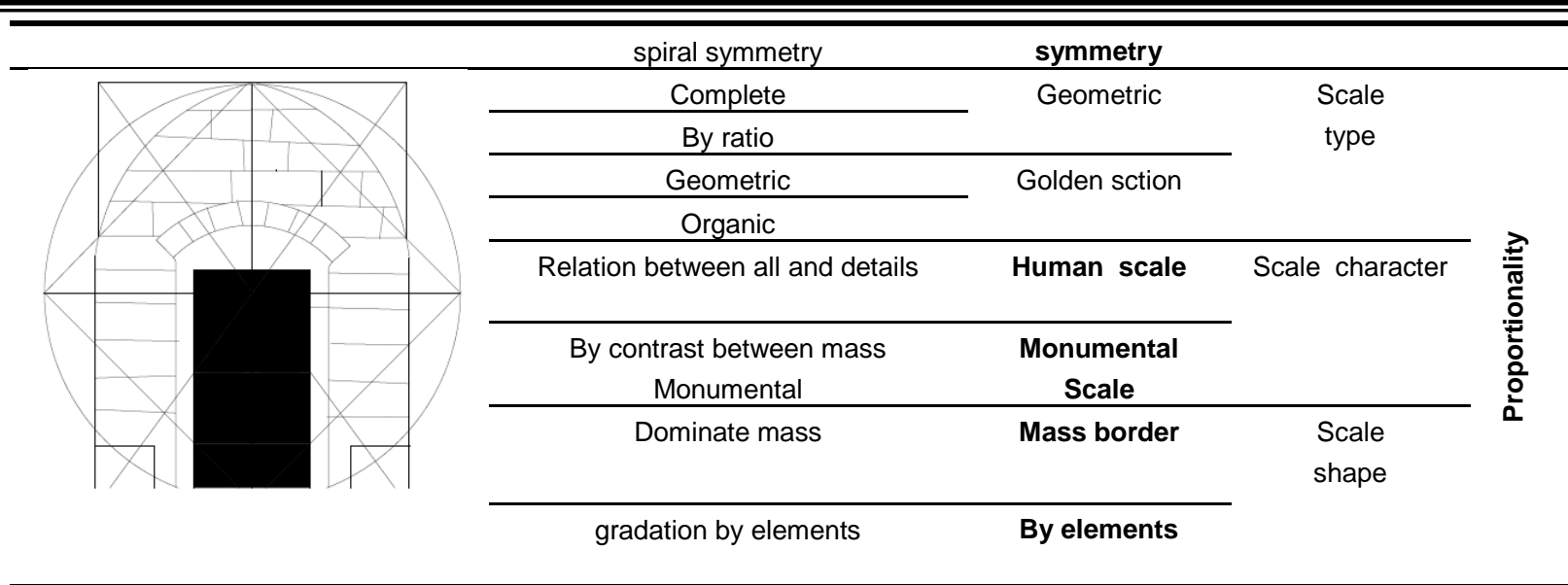

Reference: researcher

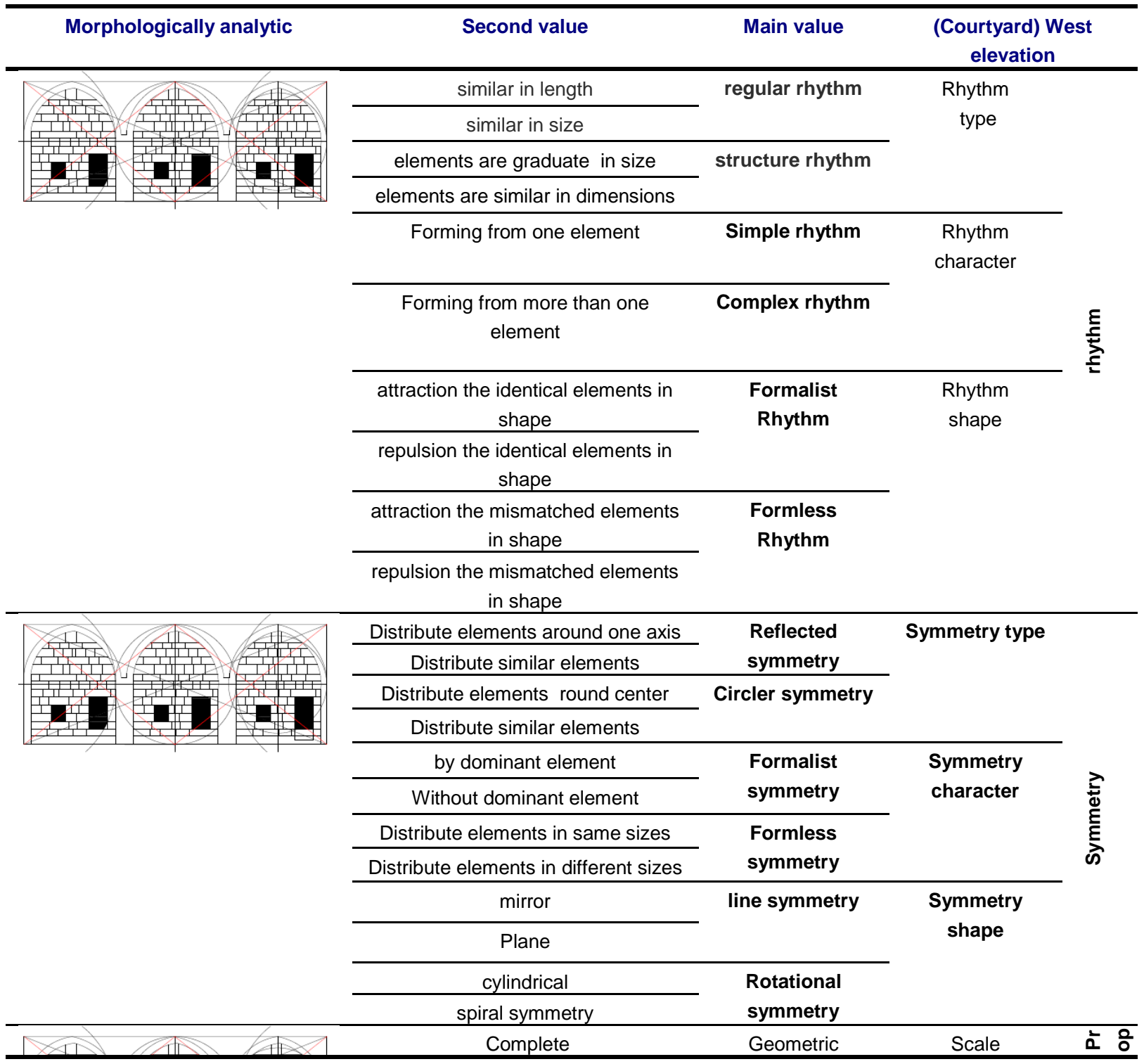




\begin{tabular}{ccc}
\hline By ratio & & type \\
\hline Geometric & Golden section & \\
\hline Organic & Human scale & $\begin{array}{c}\text { Scale } \\
\text { character }\end{array}$ \\
\hline Belation between all and details & Monumental & \\
\hline By contrast between mass & Scale & Scale \\
Monumental & shape
\end{tabular}

Reference: researcher

\begin{tabular}{|c|c|c|c|c|}
\hline Morphologically analytic & Second value & Main value & \multicolumn{2}{|c|}{$\begin{array}{c}\text { (Courtyard) south } \\
\text { elevation }\end{array}$} \\
\hline & similar in length & \multirow[t]{2}{*}{ regular rhythm } & \multirow{4}{*}{$\begin{array}{l}\text { Rhythm } \\
\text { type }\end{array}$} & \\
\hline & similar in size & & & \\
\hline & elements are graduate in size & \multirow[t]{2}{*}{ structure rhythm } & & \\
\hline & elements are similar in dimensions & & & \\
\hline & Forming from one element & Simple rhythm & \multirow[t]{2}{*}{$\begin{array}{l}\text { Rhythm } \\
\text { character }\end{array}$} & \\
\hline & $\begin{array}{l}\text { Forming from more than one } \\
\text { element }\end{array}$ & Complex rhythm & & \\
\hline & $\begin{array}{c}\text { attraction the identical elements in } \\
\text { shape }\end{array}$ & \multirow[t]{2}{*}{$\begin{array}{l}\text { Formalist } \\
\text { Rhythm }\end{array}$} & \multirow[t]{4}{*}{$\begin{array}{l}\text { Rhythm } \\
\text { shape }\end{array}$} & \\
\hline & $\begin{array}{c}\text { repulsion the identical elements in } \\
\text { shape }\end{array}$ & & & \\
\hline & $\begin{array}{l}\text { attraction the mismatched elements } \\
\text { in shape }\end{array}$ & \multirow[t]{2}{*}{$\begin{array}{l}\text { Formless } \\
\text { Rhythm }\end{array}$} & & \\
\hline & $\begin{array}{l}\text { repulsion the mismatched elements } \\
\text { in shape }\end{array}$ & & & \\
\hline & Distribute elements around one axis & \multirow{2}{*}{$\begin{array}{l}\text { Reflected } \\
\text { symmetry } \\
\end{array}$} & \multirow[t]{4}{*}{ Symmetry type } & \multirow{12}{*}{ ڤ } \\
\hline & Distribute similar elements & & & \\
\hline & Distribute elements round center & \multirow[t]{2}{*}{ Circler symmetry } & & \\
\hline & Distribute similar elements & & & \\
\hline & by dominant element & \multirow{2}{*}{$\begin{array}{l}\text { Formalist } \\
\text { symmetry }\end{array}$} & \multirow{4}{*}{$\begin{array}{l}\text { Symmetry } \\
\text { character }\end{array}$} & \\
\hline & Without dominant element & & & \\
\hline & Distribute elements in same sizes & \multirow{2}{*}{$\begin{array}{l}\text { Formless } \\
\text { symmetry }\end{array}$} & & \\
\hline & Distribute elements in different sizes & & & \\
\hline & mirror & \multirow[t]{2}{*}{ line symmetry } & \multirow{4}{*}{$\begin{array}{l}\text { Symmetry } \\
\text { shape }\end{array}$} & \\
\hline & Plane & & & \\
\hline & cylindrical & \multirow{2}{*}{$\begin{array}{l}\text { Rotational } \\
\text { symmetry }\end{array}$} & & \\
\hline & spiral symmetry & & & \\
\hline & Complete & \multirow[t]{2}{*}{ Geometric } & \multirow[t]{3}{*}{ Proportion type } & \multirow{3}{*}{ 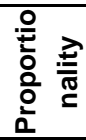 } \\
\hline & By ratio & & & \\
\hline & Geometric & Golden sction & & \\
\hline
\end{tabular}




\begin{tabular}{ccc} 
Organic & & \\
\hline Relation between all and details & Human scale & $\begin{array}{c}\text { Scale } \\
\text { character }\end{array}$ \\
\cline { 1 - 2 } By contrast between mass & $\begin{array}{c}\text { Monumental } \\
\text { Scale }\end{array}$ & \\
\hline Monumental & Mass border & $\begin{array}{c}\text { Scale } \\
\text { shape }\end{array}$ \\
\hline gradation by elements & By elements &
\end{tabular}

Reference: researcher

\begin{tabular}{|c|c|c|c|c|}
\hline Morphologically analytic & Second value & Main value & \multicolumn{2}{|c|}{$\begin{array}{l}\text { North part elevation } \\
\text { (great Iwan) }\end{array}$} \\
\hline & similar in length & \multirow[t]{2}{*}{ regular rhythm } & \multirow{4}{*}{$\begin{array}{l}\text { Rhythm } \\
\text { type }\end{array}$} & \\
\hline & similar in size & & & \\
\hline & elements are graduate in size & \multirow[t]{2}{*}{ structure rhythm } & & \\
\hline & elements are similar in dimensions & & & \\
\hline & Forming from one element & Simple rhythm & \multirow{2}{*}{$\begin{array}{l}\text { Rhythm } \\
\text { character }\end{array}$} & \\
\hline & $\begin{array}{l}\text { Forming from more than one } \\
\text { element }\end{array}$ & Complex rhythm & & \\
\hline & $\begin{array}{l}\text { attraction the identical elements in } \\
\text { shape }\end{array}$ & \multirow[t]{2}{*}{$\begin{array}{l}\text { Formalist } \\
\text { Rhythm }\end{array}$} & \multirow[t]{4}{*}{$\begin{array}{l}\text { Rhythm } \\
\text { shape }\end{array}$} & \multirow[b]{4}{*}{ 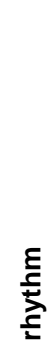 } \\
\hline & $\begin{array}{l}\text { repulsion the identical elements in } \\
\text { shape }\end{array}$ & & & \\
\hline & attraction the mismatched elements & $\begin{array}{l}\text { Formless } \\
\text { Rhvthm }\end{array}$ & & \\
\hline & $\begin{array}{l}\text { repulsion the mismatched elements } \\
\text { in shape }\end{array}$ & Rhythm & & \\
\hline & Distribute elements around one axis & \multirow{2}{*}{$\begin{array}{l}\text { Reflected } \\
\text { symmetry }\end{array}$} & \multirow[t]{4}{*}{ Symmetry type } & \multirow{12}{*}{ के } \\
\hline & Distribute similar elements & & & \\
\hline & Distribute elements round center & \multirow[t]{2}{*}{ Circler symmetry } & & \\
\hline & Distribute similar elements & & & \\
\hline & by dominant element & \multirow{2}{*}{$\begin{array}{l}\text { Formalist } \\
\text { symmetry }\end{array}$} & \multirow{4}{*}{$\begin{array}{l}\text { Symmetry } \\
\text { character }\end{array}$} & \\
\hline & Without dominant element & & & \\
\hline & Distribute elements in same sizes & \multirow{2}{*}{$\begin{array}{l}\text { Formless } \\
\text { symmetry }\end{array}$} & & \\
\hline & Distribute elements in different sizes & & & \\
\hline & mirror & \multirow[t]{2}{*}{ line symmetry } & \multirow{4}{*}{$\begin{array}{l}\text { Symmetry } \\
\text { shape }\end{array}$} & \\
\hline & Plane & & & \\
\hline & cylindrical & \multirow{2}{*}{$\begin{array}{l}\text { Rotational } \\
\text { symmetry }\end{array}$} & & \\
\hline & spiral symmetry & & & \\
\hline & Complete & \multirow[t]{2}{*}{ Geometric } & \multirow{4}{*}{$\begin{array}{l}\text { Scale } \\
\text { type }\end{array}$} & \multirow{5}{*}{ 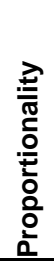 } \\
\hline & By ratio & & & \\
\hline & Geometric & \multirow[t]{2}{*}{ Golden section } & & \\
\hline & Organic & & & \\
\hline & Relation between all and details & Human scale & Scale & \\
\hline
\end{tabular}




\begin{tabular}{lll}
$\begin{array}{lll}\text { By contrast between mass } \\
\text { Monumental }\end{array}$ & $\begin{array}{l}\text { Monumental } \\
\text { Scale }\end{array}$ & character \\
\hline Dominate mass & Mass border & $\begin{array}{l}\text { Scale } \\
\text { shape }\end{array}$ \\
\cline { 1 - 2 } gradation by elements & By elements &
\end{tabular}

Reference: researcher

From previously tables we can distinguish, shapes of the internal elevations of the Qubahan school have a number of formalism characteristics represented by (rhythm, Symmetry Proportionality), as follows:

1. Rhythm: for the rhythm type the architects used the regular rhythm in all elevation expect that include great Iwan rhythm by structure which was adopted elements are graduate in size. While in rhythm character all elevations were characterized by Complex rhythm by forming from more than one element except entrance face, it was forming from one element as simple rhythm. As for rhythm shape it was formalist rhythm for all elevations in same way (repulsion the identical elements in shape).

2. Symmetry: for all elevations, symmetry type was reflected which was depending on attraction in the identical elements in shape. The same thing for Symmetry character it is a formalist symmetry by dominant element for all elevations. While the symmetry shape for all elevation was line symmetry as a main value and mirror as second value.

3. Proportionality: both type and character for all elevations are same; the type proportion was geometric materialize by ratio, like $1 / 1.17,1 / 1.8$ or 1/1.9. While the character Proportionality was human scale represented by relation between all and details, but the shape proportion has varied between mass border for entrance face and great Iwan face which represented by Dominate mass for Iwan elevation, and by elements which represent as gradation by elements to others elevation.

\subsection{The spatial system}

\section{CONCLUSIONS}

9.1.1 Conclusions on the level structure of the system as a whole (the intersection of nucleus.

The spatial system of Qubahan School has a medium comprehensiveness control as an Ayoubi pattern (alnumman ,2013).

\subsubsection{Spaces depth and integration}

1. The spaces organized in (6-8) as a level of depth and the percentage (of the number of spaces / level of depth) was $23 \%$ this ratio is close to the percentage achieved by Al-Ayoubi pattern schools were $20 \%$.

2 .The high degree of integration achieved by each of the spaces of the courtyards and arcades .that is clear reflection of the functional effect of these spaces and events that occupy edges meeting of students as a lobby of movement beside the environmental impact of the climate. As in the most Islamic buildings the spaces of school was opening towards the courtyard and closing toward outer space.

3. Classrooms Spaces have achieved High Isolation degree, this value of isolation shown clearly reflect the requirements of these spaces and what its need from being quietly as a teaching effectiveness.

4. The higher integration values of entrance space as same as in school buildings of Ayoubi pattern (alummary, p.49 2013)

5. Integration values of administrative spaces ranged about medium values this value of integration shown clearly reflect the requirements of these spaces as well as the nature of the users of these spaces also don't their intersection movement with the user's movement of the building from the students, unless in the corridors and courtyards.

6. The mosque achieved high integration value this feature may seems a clear reflection of the disappearance of the Al-Rrewaq space in these buildings. This value is close from the value of the school constructed by the Abbasid and Al-Ayoubi pattern. (alummary p. 47,2013)

7. The High integration values of (courtyard and corridors) in the open space pattern buildings are indicated the flexibility of movement in the spaces of the school, which applies to the most of the Islamic buildings school in different patterns.

\subsection{Conclusions the principles of architectural composition.}


1. The unity is the most important features of morphological characteristics at the level of the internal elevations of Qubahan School, where the system of these properties are (rhythm, symmetry and proportion), Where it formed a unified system creates by whole basic lines of general shape and interior elevations of school.

2 . These interfaces have been characterized by on formalism characteristics level on diverse rhythm and consistent with the overall visual context. It has been used geometric proportions of a square shape, which is characterized by stability and balance.it also characterized in human scale in whole system and its part.

3. The Iwan element by its (size and location) was clear effects to organize the school interior elevation, where it had influence on creates the harmonious repetition with the other elements in the interior elevation. Also it considered as a starting point for other factors in order, and it had a clear role in the stability of the interface in despite of the change in size and scale in the formation and its structures and sensor human scale.

From the results above we can conclude that the architecture of Qubqhan School is an original Islamic architecture, its style is Ayoubi pattern, and it has all principles of Islamic architecture in interior elevations (rhythm, symmetry and Proportionality) that has been influenced in environmental condition. And the Kurdish architect deals successfully with the functional and special requirements of school.

\section{REFERENCE}

1. Al-ummary, hafsa, Al-numman, raeed (Variation of Styles in Islamic Architecture and Effects it on The Changing of The Spatial Configuration of Madrasat Buildings), alrafedeen engineering, Mosul University, journal Volume: 21, No. 42013

2. Amorim and Luiz, "The sector program in space syntax", University College London, space syntax, First International Symposium. Volume II. The Bartlett School of Graduate Studies. London, (1997)

3. boisvert, and Rand Charles Stevenson (The Stander Encyclopedia of Philosophy) http/ www.digital.web.com/articels/ principle of design, 2011.
4. Carl Novjak, and Nermin Ali Mohamed Amin,

(The Study of Archaeological School Quabhan) Subartu Vol.4 -5, 2011.

5. Ching, F. D.K. (Architecture: Form, Space and Order), Van Nostrand Reihold Co. 1997.

6. Dalia Samir, (The impact of Technological Development on the Architectural Configuration), Master Thesis, Faculty of Engineering, 2005.

7. David Chalabi, scripts (Mosul and the search for religious schools), and schools of accessories, publications Euphrates Press, BAGHDAD, 1927.

8. Doris Schattschneider. (The Plane Symmetry Groups: Their Recognition and Notation the American Mathematical Monthly), Vol. 85, No. 6, (Jun.-Jul., 1978), Published by: Mathematical Association of America.

9. Graves, Maitland, (The Art of Color and Design), the Maple press company, York,. Press, England-1984.

10. Hillier, B, (Space Is the Machine), Cambridge university press, Cambridge, 1996

11. Hillier, B. and Hanson, (Social Logic of Space), Cambridge University press, Cambridge (1984).

12. Najeel Abdul Razzaq, M series Fawzi Abbas),(The Formation of Interfaces in Residential Complexes and its Impact on the Urban landscape of Dinah Baghdad) Journal of Engineering and Technology, Vol. 26, No. 5, 2008.

13. Rubensten, M.Harvey, (A Gide to Site and Environmental Planning), John Wiley and sons, INC, USA, 1969.

14. Salingaros, Nikos (Hierarchical Cooperation in Architecture, and The

Mathematical Necessity for Ornament) Journal of Architectural and Planning,

Research, Volume (17)-2000.

15. Scott, Robert Gillam (Design Fundamentals) McGraw Hill Company Inc.-1975.

16. To Tonna, (The Poftics of Arab-Islamic Architecture), Malta, 1990.

17. Tzonis, Alexander , and lefaire(Classical Architecture-The Poetics Of Order) Mit press,England, 1984.

Internet Source

1. (http://dx .doi.org/10.1016/j.foar.2012.02.003)

2. (http://www.nsta.org/publications/story.asppx?id=53 719).

3. (http://www.dainst.org/ Sonderdruck aus Zeitschritft fur orient-Archaologie Zangi-period architecture in Iraq Kurdistan Madrasa Qubahan at Amedi (Amadya) , band 4, 2011. 